\title{
Avaliação da educação superior nas modalidades presencial e a distância: análises com base no Conceito Preliminar de Cursos (CPC)
}

\author{
Édison Trombeta de Oliveira
}

Stela Conceição Bertholo Piconez

Resumo: O Conceito Preliminar de Cursos (CPC), componente do Sistema Nacional de Avaliação da Educação Superior (Sinaes), é um índice que permite observações gerais em nível nacional, um aspecto importante da política educacional pública brasileira. O presente artigo tem como base os dados do CPC para analisar as avaliações dos cursos de graduação presenciais e a distância (EaD) no Brasil. Esta análise não tem como propósito comparar as duas modalidades de ensino nem delimitar qual é a ideal ou o parâmetro a ser adotado. Breve discussão das políticas de avaliação da educação superior brasileira e da expansão deste nível nos últimos anos, com ênfase na EaD, serão apresentadas e debatidas com os dados obtidos no Portal eMec. Pôde-se observar uma distribuição bastante diferente entre os cursos presenciais e a distância. Nas graduações a distância, mais de $65 \%$ delas se situam no conceito 3. Tal conceito refere-se ao mínimo para não ter o risco de sofrer intervenção externa, segundo a legislação vigente. Na modalidade presencial, este número está em torno de 50\%. Pode-se depreender dos dados, que os cursos a distância, realizam o mínimo para não passarem por avaliação in loco, bem como esses números podem ser consequência da resistência das instituições de excelência em ofertar cursos a distância.

Palavras-chave: Educação superior. Avaliação. Educação a distância. Conceito Preliminar de Cursos.

\section{Evaluation of higher education in terms face and distance: analysis based on the Preliminary Concept of Courses (CPC)}

Abstract: Preliminary Concept of Courses (CPC), a component of the National Higher Education Evaluation System (Sinaes), is an index that allows general observations at national level, an important point for Brazilian public education policy. This paper is based on CPC statistics data to analyze the evaluations of classroom undergraduate courses and distance learning (DL) in Brazil. This analysis is not intended to compare the two types of education or define what is the ideal or the parameter to be adopted. Brief discussion of the evaluation of policies in Brazilian higher education and the expansion of this level in recent years, with emphasis on distance learning, will be presented and discussed the data obtained in the Portal EMEC. It was observed a very different distribution between the classroom undergraduate courses and distance education courses. Graduations by distance learning, over $65 \%$, are in the concept 3. This concept refers to the minimum in order to have not the risk of external intervention, according to current legislation. In the face mode, this number is around $50 \%$. It can be deduced from data that distance courses seem to perform the minimum to not go through on-site evaluation, and these numbers may be a result of the resistance of the excellence of institutions offering distance learning courses

Key words: Higher education. Evaluation. Distance learning. Preliminary Concept of Courses. 


\section{Introdução}

A meta 12 do Plano Nacional de Educação (PNE) para o decênio 2014-2024 estabelece pontos a serem atingidos, especificamente sobre a graduação brasileira. Deve-se:

\footnotetext{
elevar a taxa bruta de matrícula na educação superior para 50\% (cinquenta por cento) e a taxa líquida para $33 \%$ (trinta e três por cento) da população de 18 (dezoito) a 24 (vinte e quatro) anos, assegurada a qualidade da oferta e expansão para, pelo menos, $40 \%$ (quarenta por cento) das novas matrículas, no segmento público (BRASIL, 2014).
}

Tal meta apresenta desafios para ser atingida sem os cursos apoiados por tecnologias, ou ofertados por Educação a Distância $(\mathrm{EaD})$, o que se enquadraria na "utilização de diferentes modalidades" (SANTOS; FERREIRA, 2015, p. 57). O próprio PNE coloca a EaD como estratégia em várias metas - a estratégia 12.2, por exemplo, envolve a ampliação de vagas também pelo sistema Universidade Aberta do Brasil (UAB) -, o que torna essencial pensar a avaliação e a qualidade dos cursos ofertados nesta modalidade.

Essa discussão é significativa ao se problematizar o papel da EaD não enquanto única responsável pela precarização e pelas formações inadequadas ao contexto atual, mas sim como mais uma das consequências do processo de expansão dos últimos governos democráticos brasileiros e do talvez não suficiente processo de avaliação existente. "Um dos avanços mais significativos [...] constitui-se na tendência, expressa em trabalhos recentes, de reconhecer que a EaD não se resume a uma estratégia de mercantilização e privatização do ensino, via organismos internacionais" (SEGENREICH, 2009, p. 219).

É neste sentido que o presente artigo analisa, com base no Conceito Preliminar de Cursos (CPC), componente do Sistema Nacional de Avaliação da Educação Superior (Sinaes), as tendências e disparidades nas avaliações dos cursos de graduação presenciais e a distância no Brasil.

São comuns as críticas ao sistema de avaliação da educação superior no país. O Sinaes é tido como referência para outras nações e é um instrumento que pode servir como índice permanente e periódico para as observações gerais em nível nacional, um ponto importante da política pública da área.

É salutar esclarecer que a discussão proposta objetiva comparar as duas modalidades de educação, que são tão distintas quanto complementares entre si. Muito menos intenta-se delimitar qual delas pode ser tomada como ideal, ou qual dos dados é o parâmetro a ser adotado. 
Avaliação da educação superior nas modalidades presencial e a distância: análises com base no Conceito Preliminar de Cursos (CPC)

Para se atingir o objetivo deste trabalho, parte-se de uma discussão a respeito das políticas de avaliação da educação superior brasileira, bem como da sua expansão nos últimos anos, com foco na EaD. Com base nesta proposta de reflexão, serão apresentados e debatidos dados conseguidos no Portal eMec, organizados em quadros e gráfico.

\section{As políticas de avaliação brasileiras, o Sinaes e o CPC}

Barreyro e Rothen (2008, p. 132) destacam, em uma retomada histórica da avaliação da educação superior brasileira, quatro principais propostas expressas nos seguintes documentos: "Programa de Avaliação da Reforma Universitária" (1983), o relatório da Comissão Nacional de Reformulação da Educação Superior "Uma Nova Política para a Educação Superior Brasileira" (1985), o "Relatório do Grupo Executivo para a Reformulação da Educação Superior" (1986) e o documento da Comissão Nacional de Avaliação do Ensino Superior "Programa de Avaliação Institucional das Universidades Brasileiras" (1993).

Algumas dessas propostas possuem caráter formativo, enquanto que outras, regulador; por vezes interna, por vezes externa ${ }^{1}$. Já nessa época, a década de 1990 , as ondas do neoliberalismo mostraram suas forças no Brasil e, na educação superior, as consequências puderam ser observadas principalmente no crescimento do setor privado, tendo como égide o discurso de que o Estado deveria realizar menos determinadas atividades, delegá-las mais e, assim, ser algo como um gestor ou Estado Avaliador. "Tanto nas visões mais democráticas como na visão gerencial, a avaliação é compreendida como mecanismo primordial na garantia da qualidade da educação ou pelo menos reveladora das mazelas da educação brasileira" (ROTHEN; BARREYRO, 2011, p. 11). Este é, conforme se verá, o ponto de partida tanto da avaliação enquanto política pública (BARREYRO; ROTHEN, 2011), que será abordada neste tópico, quanto da expansão da EaD no Brasil, do item seguinte.

Depois destas quatro propostas, ainda foi colocado em prática o Exame Nacional de Cursos (ENC), popularmente lembrado como Provão. Foi criado em 1995 e vigorou até 2003, tornando-se, durante o governo de Fernando Henrique Cardoso (FHC), aos poucos, um instrumento central da avaliação da Educação Superior do Brasil, ao lado da Avaliação das Condições de Ensino e do Censo de Educação Superior (DIAS SOBRINHO, 2010).

\footnotetext{
${ }^{1}$ Mais informações a respeito dessas quatro propostas podem ser consultadas em Barreyro e Rothen (2008).
} 
O Provão era um exame nacional escrito aplicado para concluintes de cursos de determinadas áreas que o Ministério da Educação (MEC) selecionava anualmente. Aos resultados dessa prova, “[...] sempre de longe os mais importantes, se juntavam os relatórios produzidos por especialistas, após visitas in loco, sobre as condições de ensino, com ênfase na análise do currículo, da qualificação docente e da infra-estrutura física" (DIAS SOBRINHO, 2010, p. 204).

Em tese, os resultados dessa avaliação geral serviriam para que o MEC regulasse o credenciamento, o recredenciamento ou o não credenciamento de cursos e instituições. Segundo Dias Sobrinho (2010), entretanto, efeitos punitivos não foram levados a cabo mesmo contra instituições que repetidamente obtinham resultados ruins, seja por pressão política ou por força do judiciário. Por outro lado, o ENC também tinha uma visão de que o mercado, com base na divulgação ampla e sistemática das avaliações, se "autorregularia".

O ENC é uma avaliação do produto final dos cursos de graduação, o qual forneceria ao mercado consumidor de educação a informação de quais IES ofereceriam cursos de qualidade. Para "facilitar" a interpretação pelo mercado, os resultados do exame eram apresentados em uma escola de cinco níveis: assim os cursos com conceito "A" seriam os melhores, e os com conceito "E" seriam os piores. Na ilusão de que o mercado consumidor buscaria os cursos melhor avaliados, os que não obtivessem bons resultados no exame seriam fechados ou pelo MEC ou pelo mercado consumidor (BARREYRO; ROTHEN, 2011, p. 80).

Além disso, outros problemas foram apontados no ENC, como a implementação impositiva e a impossibilidade de comparação entre anos e áreas de conhecimento diferentes. De qualquer forma, “o Provão teve o mérito de colocar a avaliação na agenda da educação superior e da própria sociedade brasileira" (DIAS SOBRINHO, 2010, p. 206).

E apesar de todas críticas, a mídia fez forte uso dos dados dessas avaliações nas suas divulgações, contribuindo fortemente para a legitimação do papel dessas avaliações na sociedade e para a manutenção do ideal de que ela seria uma prova capaz de controlar a qualidade da educação (ROTHEN et al., 2015). Assim, a mídia passou a seguir principalmente duas tendências:

[...] a primeira, sensacionalista, dando destaque aos aspectos negativos identificados; a segunda, enfatizando a elaboração de rankings e, por isso mesmo, estimulando a concorrência entre as instituições. Essas tendências colaboraram, no governo FHC (1995-2002), para a implantação da política para a educação superior que tinha como norte a regulação das instituições pelo mercado. Assim, nessa nova política, os instrumentos de avaliação instaurados, especialmente o ENC, inauguraram uma relação privilegiada com a mídia em sua divulgação massiva (BARREYRO; ROTHEN, 2011, p. 82). 
Avaliação da educação superior nas modalidades presencial e a distância: análises com base no Conceito Preliminar de Cursos (CPC)

Esta, também, é uma tendência que não se separaria, pelos anos seguintes, do processo de avaliação como um todo. Instituições de Educação Superior fortaleceram suas equipes de Marketing e investiram grandemente em publicidade. Resultados, conceitos e todos os seus desdobramentos ainda são divulgados, em faixas e outdoors, como sinônimo de qualidade por todos os rincões do Brasil. Nesses casos, é necessário atentar-se às letras miúdas ligadas às informações por meio de asteriscos ou notas de rodapé. Mais um indício (ou consequência) da mercantilização da educação superior.

Em 2003, após o governo FHC, assumiu a presidência do Brasil Luiz Inácio Lula da Silva, cujo governo perdurou até 2010. A partir daí, intentou-se mudar a visão de avaliação da educação superior por meio da criação do Sistema Nacional de Avaliação da Educação Superior (Sinaes), "produto do trabalho de quatro meses da Comissão Especial de Avaliação (CEA), integrada por destacados acadêmicos e especialistas da temática da avaliação e da educação superior, assim como membros do Ministério da Educação e representantes da União Nacional dos Estudantes" (BARREYRO, 2004, p. 42).

O resultado foi uma forma de avaliação que também era uma reação à política anterior, cujo cunho era mercantilista. Assim, “o sistema tomou o formato de três avaliações (de estudantes, de cursos e de instituições), com instrumentos, critérios, indicadores e conceitos próprios" (GIOLO, 2008, p. 852).

A avaliação dos estudantes passou a ser obtida por meio do Enade (Exame Nacional de Desempenho dos Estudantes), aplicado de três em três anos para cada área do conhecimento, aos ingressantes e aos concluintes, de forma a se observar o valor agregado do curso - ou "o processo dinâmico da formação" (GIOLO, 2008, p. 852). Inicialmente de caráter amostral e com peso menor do que o Provão possuía antes, o Enade, no percurso da política avaliativa do governo, sofreu alterações e se aproximou muito do que era o ENC no governo anterior: passou, a partir de 2010, a ser censitário e a avaliar apenas os concluintes, dando resultados dos cursos em índices de 1 a 5 (BARREYRO; ROTHEN, 2014).

A avaliação dos cursos, por sua vez, abarca três dimensões básicas, segundo Barreyro e Rothen (2011): o corpo docente (titulação e regime de trabalho), o currículo do curso e a infraestrutura (com foco especial à biblioteca). Também aqui os resultados são expressados por meio de conceitos, “[...] numa escala de 5 (cinco) níveis, para as dimensões em particular e para o conjunto das dimensões avaliadas" (GIOLO, 2008, p. 853). 
Por fim, a respeito das instituições, Giolo (2008) aponta que são examinadas sob 10 dimensões, como política de atendimento aos estudantes e sustentabilidade financeira. Essa avaliação deveria ser feita em dois momentos distintos e complementares: autoavaliação (via Comissão Própria de Avaliação - CPA) e avaliação externa (via MEC). Ao final, também saem conceitos em escala até 5 para cada dimensão e para o conjunto. Entretanto,

\footnotetext{
$\mathrm{Na}$ implementação da política de avaliação institucional explicitada na lei do Sinaes, o embate entre as duas concepções de avaliação [autoavaliação e avaliação externa] continua presente. Diversos documentos divulgados no âmbito do MEC adotaram posturas diferentes, ora enfatizando o processo interno de autoavaliação, ora enfatizando a predominância da padronização de indicadores quantitativos. Efetivamente, o ciclo proposto pelo Sinaes ainda não se concluiu da forma prevista (BARREYRO; ROTHEN, 2011, p. 83).
}

A implementação do Sinaes constitui-se de um processo dinâmico. Muito do que se previra na lei acabou se transformando com o tempo e assim foi alterada a própria regulamentação legal. Segundo Barreyro e Rothen (2014), uma dessas alterações foi a criação do Conceito Preliminar de Cursos (CPC), um índice composto pelos resultados do Enade e por outros dados que, segundo o MEC, influenciariam na qualidade dos cursos, como a qualificação e o regime de trabalho do corpo docente, o planejamento de ensino e a infraestrutura da instituição e do curso. Essa alteração gerou relativa economia aos cofres públicos, algo que pode se mostrar pouco compensador a médio e longo prazo, pelos reflexos na avaliação de fato. "O Conceito Preliminar de Curso (CPC) e o IGC são indicadores de qualidade utilizados a partir de 2008, para a dispensa da avaliação in loco de cursos e de instituições, a depender da decisão da regulação" (GRIKOSKI, 2015, p. 168).

As críticas a essa política de avaliação começam a se fortalecer por causa de uma evolução promoveu uma importante mudança em direção ao que era antes, caracterizada na proposta do ENC. "O CPC sofreu mudanças em 2009, atendendo algumas das críticas realizadas. Os resultados do Enade perderam peso, assim como a opinião dos estudantes; por sua vez, aumentou-se o peso da titulação de doutores" (BARREYRO; ROTHEN, 2014, p. $71)$.

Percebe-se, assim, a retomada da lógica dos grandes exames para regulação do sistema educacional de forma muito semelhante ao que era no período FHC, a maior crítica do atual Sinaes. "As políticas de avaliação da educação superior institucionalizaram-se. Não como um processo de emancipação [...], mas sim como uma política de controle da expansão da 
Avaliação da educação superior nas modalidades presencial e a distância: análises com base no Conceito Preliminar de Cursos (CPC)

educação privada, da qualidade da mercadoria oferecida por essas instituições" (BARREYRO; ROTHEN, 2011, p. 86).

\section{A expansão da educação superior no Brasil e sua relação com a EaD}

A reverberação do neoliberalismo na educação superior brasileira fez emergir, como uma face da moeda, o Estado avaliador e, consequentemente, da avaliação como política pública. Do outro lado da moeda está, então, o fomento ao crescimento do setor privado na educação superior, que posteriormente refletiu-se também na EaD.

Neste sentido, Mancebo, Vale e Martins (2015) estabelecem quatro eixos para a expansão a partir de 1995: a privatização, a expansão da educação superior via governo Federal (destaque para o Programa de Apoio a Planos de Reestruturação e Expansão das Universidades Federais - REUNI), a EaD e o empresariamento da pós-graduação. Após uma breve apresentação de cada um desses tópicos, será destacada a contribuição ao avanço da EaD.

A respeito da privatização, cabe recordar alguns pontos abordados por Mancebo, Vale e Martins (2015). O primeiro é que, apenas entre 1995 e 2010, as matrículas nas instituições particulares de educação superior cresceram 347,15\%. Depois, alguns fatores para o seu sucesso são conhecidos como certa "promiscuidade entre o público e o privado" vinda desde o período da Ditadura Militar (1964-1985), os programas de isenção fiscal e financiamento estudantil (como o Fundo de Financiamento Estudantil - FIES - e o Programa Universidade para Todos - PROUNI), a organização dessas instituições em grandes conglomerados e a financeirização e internacionalização da educação superior brasileira, culminando, inclusive, com diversas aberturas de capital na bolsa de valores.

Segundo Vale, Carvalho e Chaves (2014, p. 216), o atual PNE ainda reitera esse destaque à privatização, "marcado pela presença do fundo público na sustentação do setor privado, pela emergência de grandes conglomerados educacionais, pela abertura de capitais e a consequente desnacionalização das empresas de serviços educacionais”".

No entanto, no setor público também houve aumento no número de matrículas no mesmo período. Entre 1995 e 2010, a rede pública de educação teve um crescimento da ordem de 134,58\% (MANCEBO; VALE; MARTINS, 2015), bem menor do que do setor privado, mas já significativo. Esse crescimento deveu-se principalmente à expansão ocorrida 
no governo de Luiz Inácio Lula da Silva (2003-2010), especialmente por meio do REUNI (Decreto $\mathrm{n}^{\mathrm{o}}$ 6.096, de 24 de abril de 2007). O programa tem entre seus objetivos o aumento no número de vagas, especialmente as noturnas; redução das taxas de evasão; utilização das vagas ociosas; reorganização dos cursos de graduação; atualização de metodologias e tecnologias educacionais; e promoção da mobilidade estudantil (SILVA, 2014).

O terceiro ponto a ser tratado refere-se ao crescimento da pós-graduação enquanto “empresariamento do conhecimento". Aqui, segundo Mancebo, Vale e Martins (2015), dois são os prismas: o primeiro é o da competitividade, já que, na luta por recursos, ganha mais aquele que tem maior produtividade; o segundo é a ligação direta com o mercado, uma vez que a pós-graduação tem sido impelida às empresas para fazer pesquisa científica e tecnológica aplicada, com a intenção superficial de formar recursos humanos qualificados, mas também para ser uma área de pesquisa e desenvolvimento não sustentada pela empresa.

Assim, chega-se à intenção desse tópico, que é debater o crescimento da EaD no Brasil nos últimos anos. Os dados apontados por Maués, Segenreich e Otranto (2015) não deixam dúvidas desse salto quantitativo: enquanto a $\mathrm{EaD}$ representava, em 2000, 0,06\% do total de matrículas no Brasil, em 2012 esse número já estava em 18,8\%. Ocorreu:

a explosão de matrículas no período 2001-2002, que se seguiu ao PNE, com um aumento de $659,7 \%$. Houve uma quebra dessa tendência nos índices de crescimento de 2002-2003 e 2003$2004,22,6 \%$ e 19,4\% respectivamente. O ritmo acelerado de crescimento foi retomado a partir de 2004 sendo que, de 2007 a 2008, esse índice alcançou 96,9\%. A partir desse ano, o crescimento tem sido contínuo, mas de forma menos acelerada (MAUÉS; SEGENREICH; OTRANTO, 2015, p. 54).

Em 2000, segundo Mancebo, Vale e Martins (2015, p. 40), “do total de 930.179 matrículas no EaD, somente 181.602 (ou 19,52\%) encontravam-se nas instituições públicas, enquanto 748.577 (ou 80,48\%) eram da rede privada". Ainda para os autores (2015), em 2012 o percentual da rede particular já era de $83,7 \%$. Esta diferença poderia ser muito maior se não tivesse ocorrido, em 2006, a criação da Universidade Aberta do Brasil (UAB), uma fundação que se apresenta como um sistema voltado ao desenvolvimento da $\mathrm{EaD}$ a fim de expandir e interiorizar a oferta de educação superior no Brasil, especialmente as licenciaturas. "A criação do Programa Pró-licenciatura, em 2005, e da Universidade Aberta do Brasil (UAB), pelo Decreto n. 5.800/06, em 2006, institucionaliza os programas de formação de professores a distância como política pública de formação" (FREITAS, 2007, p. 1210). 
Avaliação da educação superior nas modalidades presencial e a distância: análises com base no Conceito Preliminar de Cursos (CPC)

Entretanto, diversos autores, entre os quais Freitas (2007), apontam para diversas críticas referentes à implementação da $\mathrm{UAB}$ e da $\mathrm{EaD}$ de forma geral no Brasil. Para ela, o programa UAB seria uma maneira de aligeiramento e barateamento da formação dos licenciados, "uma política compensatória, que visa a suprir a ausência de oferta de cursos regulares a uma determinada clientela, sendo dirigida a segmentos populacionais historicamente já afastados da rede pública de educação superior” (FREITAS, 2007, p. 1214). É por isso que Dourado (2008), ao falar de marcos regulatórios para a educação superior a distância, propõe o fim da dicotomia presencial versus a distância. Ambos deveriam ter:

\begin{abstract}
projeto pedagógico que garanta uma sólida formação teórico-prática, professores com formação stricto sensu, condições adequadas de oferta, de laboratórios e bibliotecas, material didático-pedagógico em cursos presenciais e a distância, ressaltando que estes últimos devem garantir, ainda e não somente, estrutura adequada de acompanhamento, por meio de encontros presenciais regulares, além de outros meios envolvendo as tecnologias de informação e comunicação (DOURADO, 2008, p. 910).
\end{abstract}

De toda forma, este é um dilema que persiste ainda atualmente, e os problemas econômicos do Brasil que eclodiram em 2015 influenciaram grandemente a UAB. Apenas para o referido ano, estavam previstas 45 mil novas vagas, no entanto nenhuma teria sido preenchida após a determinação do corte de "gastos" que os ministérios deveriam realizar (PALHARES, 2015).

Em relação ao setor privado, a justificativa para a expansão da EaD é certa "exaustão da oferta de cursos presenciais (que haviam se expandido de forma extraordinária nos últimos anos do século XX), o que remeteu a fração da burguesia brasileira que detém essa fatia de mercado à busca de novos espaços para a expansão e realização de seus lucros” (MANCEBO; VALE; MARTINS, 2015, p. 41).

Grandes conglomerados educacionais na modalidade de EaD acabaram por influenciar nos números, nas condições de trabalho e de formação. Ao visar o lucro sempre exponencial, esses grupos educacionais são resultados de fusões entre grandes instituições ou da compra de algumas pequenas pelas maiores. Evidentemente, a fim de permitir padronização de procedimentos, conteúdos, materiais etc., ocorre uma concentração de matrículas em torno desses grandes grupos. Ao analisar dados do INEP (Instituto Nacional de Estudos e Pesquisas Educacionais Anísio Teixeira), Segenreich e Neves (2015, p. 127) apontam que "as sete IES [Instituições de Educação Superior] com maior número de matrículas em cursos de graduação 
a distância em 2013 representam 61,9\% do total das 165 IES que perfazem 1.152 .572 matrículas".

\section{Dados e análises}

Os dados que serão apresentados foram obtidos por meio de pesquisa feita no Portal eMec (E-MEC), um site do Ministério da Educação que contém informações a respeito de instituições de educação superior e cursos de graduação do Brasil. Cabe ressaltar que as IES dos sistemas educacionais são reguladas e supervisionadas pelos conselhos de educação de cada Estado e assim, segundo informações constantes no próprio eMec, os dados dessas IES são meramente declaratórios e de responsabilidade da sua respectiva instituição, não do MEC.

A pesquisa foi feita por meio da Consulta Avançada, selecionando-se as seguintes opções: em "Busca por" foi marcado apenas "Curso de Graduação"; em "Modalidade", inicialmente "A Distância" e depois "Presencial"; em "Índice", selecionou-se "CPC" e foi consultado um conceito por vez; por fim, em "UF", primeiro buscou-se sem fazer qualquer seleção (âmbito nacional) e, depois, apenas por São Paulo. Os demais campos ficaram sem seleção específica. Desta forma, a pesquisa englobou cursos de bacharelado, licenciatura, tecnólogo e sequencial. Além disso, traz a última nota do CPC inserida no sistema, o que pode fazer com que o ano do conceito varie de curso para curso, bem como de instituição para instituição. Também por isso, vale destacar que os quadros a seguir, organizadas pelo pesquisador, contêm a indicação, por meio de nota de rodapé, da data da pesquisa, uma vez que a inserção de novas informações é dinâmica e pode ser alterada a qualquer momento.

Um último destaque a se fazer a respeito dos procedimentos de pesquisa e dos dados que se seguirão envolve a contagem dos cursos oferecidos: no portal eMec, cada polo de um curso de graduação na modalidade $\mathrm{EaD}$ é contado como um curso; já com relação ao presencial, a contagem é mais clara (cada curso é um curso). Assim, pode parecer que os dados estão "inflados" quando se analisa os cursos na modalidade a distância, no entanto não se pode esquecer que a infraestrutura de um polo pode ser bastante diferente da de outro, o que justificaria alguma alteração no conceito. Além disso, se os dados fossem disponibilizados apenas pelo Estado de oferta do curso, por exemplo, e não de cada polo, ocorreria uma distorção na visualização da oferta. Se se contabilizasse as matrículas de todos os polos como se fossem da instituição sede, ocorreria uma inobservância de uma " [...] 
Avaliação da educação superior nas modalidades presencial e a distância: análises com base no Conceito Preliminar de Cursos (CPC)

especificidade do modelo brasileiro de educação a distância no que se relaciona à possibilidade de oferta de cursos em polos não sediados na sede da instituição" (MAUÉS; SEGENREICH; OTRANTO, 2015, p. 53).

O primeiro quadro - Quadro 1, a seguir, é um condensado nacional dos CPC, separados por modalidade de ensino e incluindo os cursos sem conceito. As informações estão dispostas em números brutos e em porcentagem.

Quadro 1 - CPC, por conceito e por modalidade de curso, no Brasil ${ }^{2}$

\begin{tabular}{|c|c|c|c|c|}
\hline Conceito & Presencial & $\%$ & EaD & $\%$ \\
\hline $\mathbf{1}$ & 92 & $0,4 \%$ & 1942 & $0 \%$ \\
\hline $\mathbf{2}$ & 2972 & $14,4 \%$ & 16314 & $65,2 \%$ \\
\hline $\mathbf{3}$ & 9201 & $44,7 \%$ & 5053 & $20,2 \%$ \\
\hline $\mathbf{4}$ & 4918 & $24 \%$ & 187 & $0,7 \%$ \\
\hline $\mathbf{5}$ & 404 & $2 \%$ & 1531 & $6,1 \%$ \\
\hline Sem Conceito & 2971 & $14,5 \%$ & 25027 & $100 \%$ \\
\hline Total & 20558 & $100 \%$ & 0 \\
\hline
\end{tabular}

Fonte: elaborada pelos autores

A respeito deste quadro, pode-se perceber que há uma concentração maior, entre os cursos a distância, no conceito $3(65,2 \%)$ em comparação com os cursos presenciais $(44,7 \%)$. Consequentemente, há menos cursos nas áreas tidas como "de excelência", com conceitos 4 e 5 (20,9\% ante $26 \%$ no presencial), bem como no campo dos cursos mal avaliados, com conceitos 1 e 2 (7,8\% ante $14,8 \%$ nos presenciais).

Também pode-se observar uma considerável diferença entre os cursos sem conceito (14,5\% para a modalidade presencial e $6,1 \%$ para cursos a distância, uma diferença $8,4 \%$ a mais para os presenciais). Registre-se que, segundo Nota Técnica do INEP (2014), ficam Sem Conceito no CPC os cursos que não possuam "no mínimo 2 (dois) ingressantes inscritos no Enade e 2 (dois) concluintes inscritos participantes no Enade". Tal fato pode ser reflexo da dificuldade de alguns cursos presenciais em sobreviveram frente à crescente oferta por cursos

\footnotetext{
${ }^{2}$ Pesquisa realizada no site em 20 de novembro de 2015.
} 
a distância e ao aumento da participação dos grandes conglomerados educacionais, que podem baixar o preço dos cursos e tornar a "competição" por estudantes mais difícil às pequenas IES. Mancebo, Vale e Martins (2015, p. 37) já indicaram algo semelhante:

Outra tendência a se considerar no período em estudo quanto ao fortalecimento da iniciativa privada envolve a organização de grandes conglomerados, o que significa que o setor tem se consolidado em uma economia de escala, em que grandes grupos oferecem ensino superior barato, com uma qualidade sofrível, uso ampliado de EaD etc.

Isso pode ser depreendido também do quadro 2, a seguir, que divide os cursos Sem Conceito entre modalidade e gratuidade ou não.

\section{Quadro 2 - Cursos com CPC Sem Conceito, por modalidade e por gratuidade ou não, no Brasil ${ }^{3}$}

\begin{tabular}{|c|c|c|}
\hline Caracterização do curso & Quantidade & $\%$ \\
\hline Presencial gratuito & 465 & $10,1 \%$ \\
\hline EaD gratuito & 19 & $0,4 \%$ \\
\hline Presencial não gratuito & 2513 & $54,8 \%$ \\
\hline EaD não gratuito & 1591 & $34,7 \%$ \\
\hline Total & 4588 & $100 \%$ \\
\hline
\end{tabular}

Fonte: elaborada pelos autores

Este quadro aponta que a maioria dos cursos sem conceito, ou seja, que não tiveram pelo menos dois alunos ingressantes inscritos e dois concluintes participantes no Enade, está concentrada nos cursos presenciais não gratuitos - privados - $(54,8 \%)$, seguido dos cursos EaD privados. É o mercado que mais parece estar com dificuldades de abrir e/ou formar turmas, em especial nos cursos presenciais. Segundo Vale, Carvalho e Chaves (2014, p. 204):

As empresas educacionais passaram a adotar novas estratégias em face da concorrência acirrada promovido pelo surto expansivo dos anos 1990. Na busca por "clientes", entraram em cena desde a diversificação de cursos [...], bem como, para algumas IES, a solução foi se especializarem em um determinado nicho acadêmico, direcionadas ao extrato de maior renda [...]. Outras maneiras de conquistar a clientela incluem desde a adoção de marketing agressivo direcionado pelo discurso do acesso imediato ao mercado de trabalho, mediante o uso da imagem de artistas e/ou modelos como exemplos de pessoas bem sucedidas, até a divulgação

\footnotetext{
${ }^{3}$ Pesquisa realizada no site em 14 de dezembro de 2015.
} 
Avaliação da educação superior nas modalidades presencial e a distância: análises com base no Conceito Preliminar de Cursos (CPC)

de promoções nos valores das mensalidades, em clara competição predatória com o intuito de baratear para obter ganho em escala.

Ainda sobre este tema, uma ressalva é que, segundo as mesmas autoras, tudo isso parece ainda não ser suficiente para sustentar as IES fragilizadas pela ferrenha concorrência do mercado frente às grandes taxas de inadimplência e de desistência durante o curso (VALE; CARVALHO; CHAVES, 2014).

Quadro 3 - CPC, por conceito e por modalidade de curso, no Brasil, desconsiderando-se os cursos sem conceito ${ }^{4}$

\begin{tabular}{|c|c|c|c|c|}
\hline Conceito & Presencial & $\%$ & EaD & $\%$ \\
\hline $\mathbf{1}$ & 92 & $0,5 \%$ & 1942 & $8,3 \%$ \\
\hline $\mathbf{2}$ & 2972 & $16,9 \%$ & 16314 & $69,4 \%$ \\
\hline $\mathbf{3}$ & 9201 & $52,3 \%$ & 5053 & $21,5 \%$ \\
\hline $\mathbf{4}$ & 4918 & $28 \%$ & 187 & $0,8 \%$ \\
\hline $\mathbf{5}$ & 404 & $2,3 \%$ & 23496 & $100 \%$ \\
\hline Total & 17587 & $100 \%$ & 0 \\
\hline
\end{tabular}

Fonte: elaborada pelos autores

Desconsiderando-se os cursos Sem Conceito no CPC, a porcentagem dos cursos a distância com nota 3 chama mais a atenção: são 69,4\%, ante 52,3\% nos presenciais. Dessa diferença de $17,1 \%$, pode-se depreender alguns pontos. Inicialmente, os cursos a distância podem estar "confortáveis" com a nota 3, a mínima para não sofrer intervenção externa, o que não os torna nem de referência e nem de baixa qualidade. Isso porque Barreyro e Rothen (2014, p. 70) explicitam que após a criação do CPC, as visitas in loco ficaram restritas "aos cursos que obtiveram um conceito preliminar menor que 3 , o que gerou a diminuição de 3.000 visitas previstas por ano para 1.800 ”.

Por outro lado, como parte do conceito é concedida por avaliadores com ampla trajetória na educação presencial, eles próprios podem ser sujeitos da "imagem" amplamente difundida da baixa qualidade dos cursos a distância - assim, aprovam o curso com o mínimo

\footnotetext{
${ }^{4}$ Pesquisa realizada no site em 20 de novembro de 2015.
} 
necessário. Por fim, esses dados ainda podem ser consequência da falta de participação das instituições de excelência (na maioria, públicas) na oferta de cursos a distância, uma vez que boa parte destas ainda resiste em oferecer cursos na modalidade, apesar do esforço do governo federal por meio do programa $\mathrm{UAB}$, que fez aumentar a matrícula na $\mathrm{EaD}$ pública por volta de 2008, mas depois perdeu força (MANCEBO; VALE; MARTINS, 2015).

Por fim, o quadro 4 e o gráfico a seguir demonstram informações condensadas sobre os CPC e as respectivas porcentagens dos cursos, separados em quatro categorias: presenciais gratuitos, presenciais não gratuitos, $\mathrm{EaD}$ gratuitos e $\mathrm{EaD}$ não gratuitos. A pesquisa envolveu os cursos de todo o país e também descartou os Sem Conceito. O gráfico foi construído com base em todos os dados dispostos no quadro.

Quadro 4 - CPC, por modalidade e gratuidade ou não, no Brasil, desconsiderando-se os Sem Conceito ${ }^{5}$

\begin{tabular}{|l|c|c|c|c|c|c|c|c|c|c|c|}
\hline & $\mathbf{1}$ & \multicolumn{1}{c|}{$\%$} & $\mathbf{2}$ & \multicolumn{1}{c|}{$\%$} & $\mathbf{3}$ & $\%$ & $\mathbf{4}$ & $\%$ & $\mathbf{5}$ & $\%$ & Total \\
\hline Pres. grat. & 20 & - & 510 & $1,3 \%$ & 1721 & $4,2 \%$ & 1735 & $4,2 \%$ & 209 & $0,5 \%$ & 4195 \\
\hline EaD grat. & 0 & - & 0 & - & 65 & $0,2 \%$ & 144 & $0,4 \%$ & 68 & $0,2 \%$ & 277 \\
\hline Pres. não grat. & 72 & $0,2 \%$ & 2462 & $6 \%$ & 7480 & $18,2 \%$ & 3183 & $7,7 \%$ & 195 & $0,5 \%$ & 13392 \\
\hline EaD não grat. & 0 & - & 1942 & $4,7 \%$ & 16249 & $39,5 \%$ & 4909 & $11,9 \%$ & 119 & $0,3 \%$ & 23219 \\
\hline & 92 & $0,2 \%$ & 4914 & $12 \%$ & 25515 & $62,1 \%$ & 9971 & $24,2 \%$ & 591 & $1,5 \%$ & 41083 \\
\hline
\end{tabular}

Fonte: elaborada pelos autores

\footnotetext{
${ }^{5}$ Pesquisa realizada no site em 20 de novembro de 2015.
} 


\section{Gráfico 1 - CPC, por modalidade e gratuidade ou não, no Brasil, desconsiderando-se os Sem Conceito}

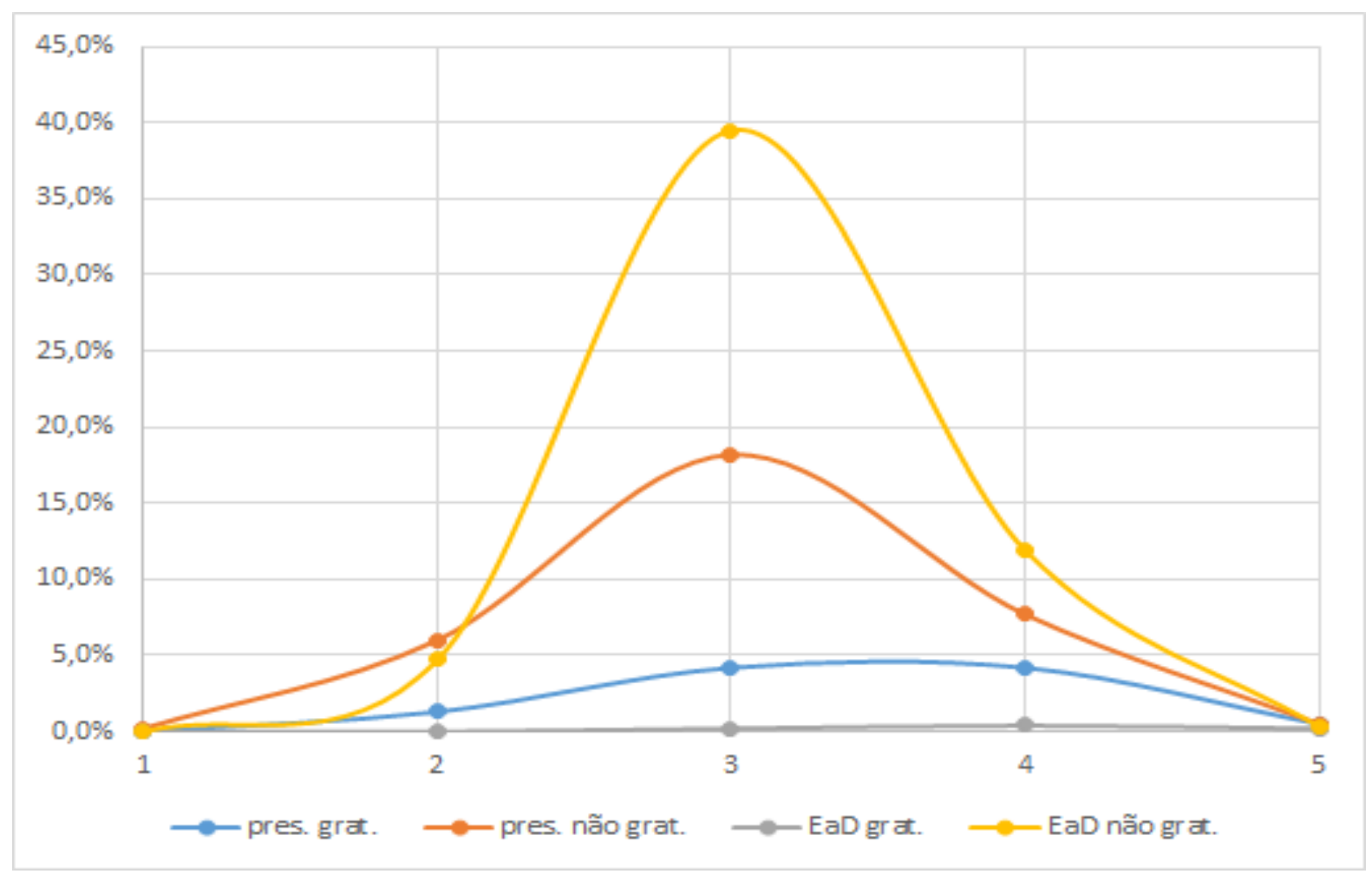

Fonte: elaborado pelos autores

A partir do quadro, duas inferências conhecidas podem ser feitas. A primeira é a baixa participação dos cursos gratuitos frente à oferta nacional; a segunda é a reduzida existência de cursos gratuitos a distância, algo que vem a reforçar a hipótese da falta das instituições de excelência na oferta dessa modalidade. Isso porque, como se sabe, as faculdades públicas costumam concentrar as melhores notas no CPC.

Convém observar no Gráfico 1 que há dois tipos de curvas quando se relaciona os conceitos e as categorias: enquanto que os cursos gratuitos (tanto presenciais quanto a distância) são menos representativos e ficam mais agregados nos conceitos 3 e 4, uma linha mais constante, é visível que os cursos não gratuitos estão concentrados, com uma forte curva, apenas no conceito 3. Esses dados reforçam o que já foi dito anteriormente, a respeito de se conseguir a nota 3 enquanto mínima para não sofrer intervenções externas, agora ampliando a dedução para todos os cursos pagos.

A discrepância nas curvas entre $\mathrm{EaD}$ gratuito e $\mathrm{EaD}$ não gratuito é imensa, o que denota a mercantilização ainda presente nessa modalidade de educação. É necessário apontar que isso é reflexo da mercantilização como um todo, se fazendo presente com mais força em um nível pouco regulado e no qual as IES públicas ainda resistem em oferecer. 


\section{Considerações finais}

Retomar o objetivo deste trabalho, ou seja, analisar as estatísticas das avaliações de cursos de graduação do Brasil, tanto presenciais quanto a distância, com base nos conceitos do CPC desvela a distribuição bastante diferente entre os conceitos dos cursos presenciais e a distância. Neste segundo grupo, ficou visível que há uma quantidade muito maior de cursos com conceito 3, o mínimo para não passar por avaliações externas in loco.

Alguns aspectos podem ainda ser problematizados. Há que se pensar, por exemplo, que os cursos a distância têm realizado o mínimo para não sofrerem riscos de intervenção externa, o que reduz muito o número de cursos tidos como "de excelência" (conceitos 4 e 5), bem como os de "baixa qualidade" (conceitos 1 e 2). Uma outra consideração nos leva à percepção de que a pouca participação das instituições de excelência no campo da EaD justifica as condições de rejeição ao seu ingresso. Por fim, há que se lembrar que a avaliação desses cursos é feita por avaliadores que, por vezes, podem ter cristalizado critérios da educação presencial e de preconceitos com relação a EaD. Entre os dados dos cursos presenciais há uma maior porcentagem de "Sem Conceito", algo que pode apontar para a dificuldade de abrir e formar turmas nesta modalidade.

Retomando o PNE, pode-se perceber que qualidade da educação é uma demanda fundamental, tanto que sua melhoria está entre as diretrizes do Plano. Isso também fica estreitamente ligado à educação superior, pois a própria meta 12, que abarca a expansão desse nível de ensino, ressalta que deve ser assegurada a qualidade da oferta. E a estratégia 19 faz menção direta aos processos de avaliação, que devem, em dois anos, ser reestruturados "com ênfase na melhoria de prazos e qualidade da decisão" (BRASIL, 2014).

Urge pensar novas dimensões estratégicas de avaliação cujos efeitos contribuam para a melhoria efetiva dos cursos. As alterações que ocorrerão não podem visar apenas a economia ou a otimização de processos, mas devem ser pensadas de forma a tornar a educação superior com qualidade ampliada, seja na modalidade de educação presencial ou a distância.

Gomes (2013, p. 22) ilustra e corrobora com tal observação quando afirma:

\footnotetext{
A Educação a Distância precisa deixar de ser algo tratado à parte nas instituições escolares, de ser oferecida como uma abordagem, uma modalidade, um ramo de negócios ou apenas como uma oportunidade flexível de acesso à universidade. Porém, os novos paradigmas não podem valer apenas para uma "modalidade" educacional; essa dicotomia é inadmissível e improdutiva.
}

Ou seja, enquanto se pensar que EaD é algo totalmente separado do ensino presencial e deve ser tratado de diferentemente do presencial, a tendência é que pouco se altere nessa problematização. Como apontado nesse trabalho, a mercantilização não é uma característica 
Avaliação da educação superior nas modalidades presencial e a distância: análises com base no Conceito Preliminar de Cursos (CPC)

da EaD. Ela tem sido observada no sistema educacional como um todo. Muitos estudos sobre o tema avaliação precisam ser desenvolvidos buscando estratégias para a qualidade da educação e o pleno direito previsto na Constituição Brasileira.

\section{Referências}

BARREYRO, Gladys Beatriz. Do Provão ao Sinaes: o processo de construção de um novo modelo de avaliação da educação superior. Avaliação, Campinas; Sorocaba, v. 9, n. 1, p. 37 49, mar. 2004. Disponível em:

<http://periodicos.uniso.br/ojs/index.php?journal=avaliacao\&page=article\&op=view\&path[]= 1267\&path[]=1257>. Acesso em: 30 nov. 2015.

BARREYRO, Gladys Beatriz; ROTHEN, José Carlos. Para uma história da avaliação da educação superior brasileira: análise dos documentos do PARU, CNRES, GERES e PAIUB. Avaliação, Campinas; Sorocaba, v. 13, n. 1, p. 131-152, mar. 2008. Disponível em: <http://www.scielo.br/pdf/aval/v13n1/a08v13n1.pdf>. Acesso em: 15 dez. 2015.

BARREYRO, Gladys Beatriz; ROTHEN, José Carlos. Avaliação da educação superior como política pública. In: ROTHEN, José Carlos; BARREYRO, Gladyz Beatriz. Avaliação da educação: diferentes abordagens críticas. São Paulo: Xamã, 2011. p. 75-87.

BARREYRO, Gladys Beatriz; ROTHEN, José Carlos. Percurso da avaliação da educação superior nos Governos Lula. Educ. Pesqui., São Paulo, v. 40, n. 1, p. 61-76, jan./mar. 2014. Disponível em: 〈http://www.scielo.br/pdf/ep/v40n1/05.pdf〉. Acesso em: 1 dez. 2015.

BRASIL. Lei 13005, de 25 de junho de 2014. Aprova o Plano Nacional de Educação - PNE e dá outras providências. Diário Oficial da União, Brasília, 26 jun. 2014. Disponível em: <http://www.planalto.gov.br/ccivil_03/_ato2011-2014/2014/lei/113005.htm>. Acesso em: 21 nov. 2015.

DIAS SOBRINHO, José. Avaliação e transformações da educação superior brasileira (19952009): do provão ao Sinaes. Avaliação, Campinas; Sorocaba, v. 15, n. 1, p. 195-224, mar. 2010. Disponível em: <http://www.scielo.br/pdf/aval/v15n1/v15n1a11.pdf >. Acesso em: 15 dez. 2015.

DOURADO, Luiz Fernandes. Políticas e gestão da educação superior a distância: novos marcos regulatórios? Educ. Soc., Campinas, v. 29, n. 104 - Especial, p. 891-917, out. 2008. Disponível em: <http://www.scielo.br/pdf/es/v29n104/a1229104>. Acesso em: 19 out. 2015.

E-MEC. Brasília: Ministério da Educação. Disponível em: <http://emec.mec.gov.br/>. Acesso em: 20 nov. 2015.

FREITAS, Helena Costa Lopes de. A (nova) política de formação de professores: a prioridade postergada. Educ. Soc., Campinas, v. 28, n. 100 - Especial, p. 1203-1230, out. 2007.

Disponível em: <http://www.scielo.br/pdf/es/v28n100/a2628100>. Acesso em: 19 out. 2015.

GIOLO, Jaime. "Sinaes" intermitentes. Avaliação, Campinas; Sorocaba, v. 13, n. 3, p. 851856, nov. 2008. Disponível em: 〈http://www.scielo.br/pdf/aval/v13n3/15.pdf>. Acesso em: 30 nov. 2015. 
GOMES, Luiz Fernando. EaD no Brasil: desafios e perspectivas. Avaliação, Campinas; Sorocaba, v. 18, n. 1, p. 13-22, mar. 2013. Disponível em:

<http://periodicos.uniso.br/ojs/index.php?journal=avaliacao\&page=article\&op=view \&path[]= 1470\&path[]=1439>. Acesso em: 30 out. 2015.

GRIKOSKI, Claudia Maffini. O Sinaes e a política de desenvolvimento da educação superior. In: SOUSA, José Vieira (Org.). Expansão e avaliação da educação superior brasileira: formatos, desafios e novas configurações. Belo Horizonte: Fino Traço; Faculdade de Educação da Universidade de Brasília, 2015. p. 157-175.

INSTITUTO NACIONAL DE ESTUDOS E PESQUISAS EDUCACIONAIS ANÍSIO TEIXEIRA [INEP]. Nota Técnica $\mathbf{n}^{\mathbf{0}}$ 72: Cálculo do Conceito Preliminar de Curso referente a 2013. Brasília: INEP, 2014. Atualizada em 06 de maio de 2015. Disponível em: <http://download.inep.gov.br/educacao_superior/enade/notas_tecnicas/2013/nota_tecnica_n_ 72_2014_calculo_cpc_2013.pdf>. Acesso em: 14 dez. 2015.

MANCEBO, Deise; VALE, Andrea Araújo do; MARTINS, Tania Barbosa. Políticas de expansão da educação superior no Brasil: 1995-2010. Revista Brasileira de Educação, Rio de Janeiro, v. 20, n. 60, p. 31-50, jan./mar. 2015. Disponível em:

<http://www.scielo.br/pdf/rbedu/v20n60/1413-2478-rbedu-20-60-0031.pdf>. Acesso em: 15 dez. 2015.

MAUÉS, Olgaíses; SEGENREICH, Stella; OTRANTO, Celia. As políticas de formação de professores: a expansão comprometida. Educação em Questão, Natal, v. 51, n. 37, p. 42-72, jan./abr. 2015. Disponível em:

<http://www.periodicos.ufrn.br/educacaoemquestao/article/view/7171/5297>. Acesso em: 11 nov. 2015.

PALHARES, Isabela. Cursos federais a distância sofrem com corte de verbas. Estadão, 28 ago. 2015. Disponível em: <http://educacao.estadao.com.br/noticias/geral,cursos-federais-adistancia-sofrem-com-corte-de-verba,1752685>. Acesso em: 25 fev. 2016.

ROTHEN, José Carlos; BARREYRO, Gladys Beatriz; PRADO, Aryane de Paula; BORTOLIN, Leticia; CAVACHIA, Raiani Cristina. A divulgação da avaliação da educação na imprensa escrita: 1995-2010. Avaliação, Campinas; Sorocaba, v. 20, n. 3, p. 643-664, nov. 2015. Disponível em: <http://www.scielo.br/pdf/aval/v20n3/1414-4077-aval-20-0300643.pdf>. Acesso em: 28 jan. 2016.

ROTHEN, José Carlos; BARREYRO, Gladys Beatriz. Avaliação da educação. In: ROTHEN, José Carlos; BARREYRO, Gladyz Beatriz. Avaliação da educação: diferentes abordagens críticas. São Paulo: Xamã, 2011. p. 11-16.

SANTOS, Catarina de Almeida; FERREIRA, Suely. O Plano Nacional de Educação e os desafios da expansão da educação superior. In: SOUSA, José Vieira (Org.). Expansão e avaliação da educação superior brasileira: formatos, desafios e novas configurações. Belo Horizonte: Fino Traço; Faculdade de Educação da Universidade de Brasília, 2015. p. 55-72.

SEGENREICH, Stella Cecília Duarte; NEVES, Antônio Maurício Castanheira das. O espaço da Educação a Distância na expansão da Educação Superior Brasileira Pós-LDEN/1996. In: SOUSA, José Vieira (Org.). Expansão e avaliação da educação superior brasileira: formatos, desafios e novas configurações. Belo Horizonte: Fino Traço; Faculdade de Educação da Universidade de Brasília, 2015. p. 115-134.

SEGENREICH, Stella Cecília Duarte. ProUni e UAB como estratégias de EAD na expansão do Ensino Superior. Pró-Posições, Campinas, v. 20, n. 2, p. 205-222, maio/ago. 2009. 
Avaliação da educação superior nas modalidades presencial e a distância: análises com base no Conceito Preliminar de Cursos (CPC)

Disponível em: <http://www.scielo.br/pdf/pp/v20n2/v20n2a13.pdf>. Acesso em: $11 \mathrm{dez}$, 2015.

SILVA, Aurélio Ferreira. O Reuni entre a expansão e a reestruturação: uma abordagem da dimensão acadêmico-curricular. 2014. 183 f. Dissertação (Mestrado em Educação) Faculdade de Educação, Universidade de São Paulo, São Paulo, 2014.

VALE, Andrea Araújo; CARVALHO, Cristina Almeida; CHAVES, Vera Jacob. Expansão privado-mercantil e a financeirização da educação superior brasileira. In: CABRITO, Belmiro, et al. Os desafios da expansão da educação em países de língua portuguesa: financiamento e internacionalização. Lisboa: Educa, 2014. p.199-220.

Édison Trombeta de Oliveira - Universidade de São Paulo São Paulo | SP | Brasil. Contato: edisontrombeta@gmail.com

Stela Conceição Bertholo Piconez - Universidade de São Paulo São Paulo | SP | Brasil. Contato: stela.piconez@gmail.com aprovado em 10 de abril de 2017. 